\title{
Large-Eddy Simulation of pollutant dispersion around a cubical building: Analysis of the turbulent mass transport mechanism by unsteady concentration and velocity statistics
}

\author{
P. Gousseau ${ }^{*(a)}$, B. Blocken ${ }^{(b)}$, G.J.F. van Heijst ${ }^{(c)}$
}

(a) Building Physics and Services, Department of the Built Environment, Eindhoven University of Technology, P.O. Box 513, 5600 MB Eindhoven, The Netherlands, p.gousseau@tue.nl

(b) Building Physics and Services, Department of the Built Environment, Eindhoven University of Technology, P.O. Box 513, 5600 MB Eindhoven, The Netherlands, b.j.e.blocken@tue.nl

(c) Fluid Dynamics Laboratory, Department of Applied Physics, Eindhoven University of Technology, P.O. Box 513, 5600 MB Eindhoven, The Netherlands, g.j.f.v.heijst@tue.nl

\section{Highlights}

- Large-Eddy Simulation of pollutant dispersion around a cubical building

- Computed average and standard deviation of concentration are compared to measurements

- Contribution of subgrid scales to turbulent mass flux is evaluated

- Turbulent mass transport is analyzed by velocity and concentration statistics

- These statistics are linked to the turbulent flow structure around the building

\section{Graphical abstract}

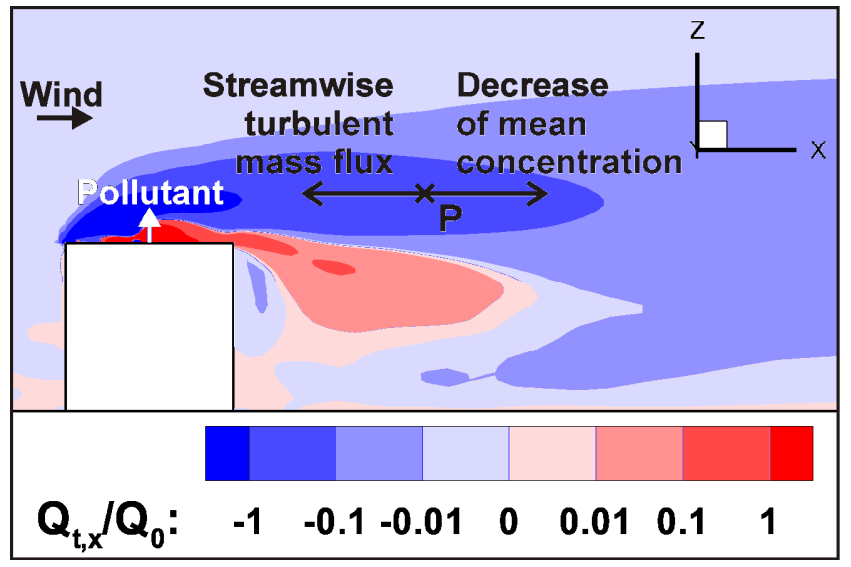

Large-Eddy Simulation

Contours of

non-dimensional

streamwise component

of the turbulent mass flux

At P:

Turbulent mass flux directed

from low to high levels of

mean concentration

Corresponding author: Pierre Gousseau, Building Physics and Services, Eindhoven University of Technology, P.O. Box 513, 5600 MB Eindhoven, The Netherlands. Tel: +31 (0)40 247 4374. Fax: +31 (0)40 2438595

E-mail address: p.gousseau@tue.nl 


\title{
Large-Eddy Simulation of pollutant dispersion around a cubical building: Analysis of the turbulent mass transport mechanism by unsteady concentration and velocity statistics
}

\author{
P. Gousseau ${ }^{*(a)}$, B. Blocken ${ }^{(b)}$, G.J.F. van Heijst ${ }^{(c)}$ \\ (a) Building Physics and Services, Department of the Built Environment, Eindhoven University of \\ Technology, P.O. Box 513, 5600 MB Eindhoven, The Netherlands, p.gousseau@tue.nl \\ (b) Building Physics and Services, Department of the Built Environment, Eindhoven University of \\ Technology, P.O. Box 513, 5600 MB Eindhoven, The Netherlands, b.j.e.blocken@tue.nl \\ (c) Fluid Dynamics Laboratory, Department of Applied Physics, Eindhoven University of Technology, \\ P.O.Box 513, 5600 MB Eindhoven, The Netherlands, g.j.f.v.heijst@tue.nl
}

\begin{abstract}
Pollutant transport due to the turbulent wind flow around buildings is a complex phenomenon which is challenging to reproduce with Computational Fluid Dynamics (CFD). In the present study we use Large-Eddy Simulation (LES) to investigate the turbulent mass transport mechanism in the case of gas dispersion around an isolated cubical building. Close agreement is found between windtunnel measurements and the computed average and standard deviation of concentration in the wake of the building. Since the turbulent mass flux is equal to the covariance of velocity and concentration, we perform a detailed statistical analysis of these variables to gain insight into the dispersion process. In particular, the fact that turbulent mass flux in the streamwise direction is directed from the low to high levels of mean concentration (counter-gradient mechanism) is explained. The large vortical structures developing around the building are shown to play an essential role in turbulent mass transport.
\end{abstract}

\section{Capsule}

Large-Eddy Simulation is used to simulate pollutant dispersion around a cubical building and to compute statistics of concentration and velocity fluctuations, which provides physical insight into the turbulent mass transport process.

\section{Keywords}

Urban wind flow; scalar transport; turbulent mass flux; counter-gradient diffusion; turbulent Schmidt number

Corresponding author: Pierre Gousseau, Building Physics and Services, Eindhoven University of Technology, P.O. Box 513, 5600 MB Eindhoven, The Netherlands. Tel: +31 (0)40 247 4374. Fax: +31 (0)40 2438595

E-mail address: p.gousseau@tue.nl 


\section{Introduction}

Computational Fluid Dynamics (CFD) is increasingly used to predict pollutant dispersion around buildings and in cities (e.g. Tominaga et al., 1997; Meroney et al., 1999; Meroney, 2004; Hanna et al., 2006; Blocken et al., 2008; Gromke et al., 2008; Balczó et al., 2009; Tominaga and Stathopoulos, 2007, 2010, 2011; Gousseau et al., 2011a, 2011b). While most of these studies used the steady Reynolds-Averaged Navier-Stokes (RANS) approach, there is a consensus on the fact that Large-Eddy Simulation (LES) is more accurate for modeling of wind flow and dispersion. LES temporally resolves the flow and dispersion equations and gives access to the concentration statistics. This is important because in many environmental applications, not only the accurate prediction of the mean flow and/or concentration field(s) is needed, but also time-dependent information. This time-resolving feature of LES also explains why this class of models generally performs better than RANS in simulating the inherently unsteady wind flow around buildings (Murakami, 1993; Rodi, 1997; Tominaga et al., 2008a) and the dispersion process itself (e.g. Tominaga and Stathopoulos, 2010, 2011; Gousseau et al., 2011a, 2011b). Consequently, LES can be used as a research tool to evaluate less sophisticated turbulence modeling approaches such as steady RANS.

With RANS, the turbulence-induced transport of concentration - and more generally, of scalars - is almost exclusively computed based on the gradient of the mean value, with the so-called gradient-diffusion hypothesis, or first-order closure (Franke et al., 2007, 2011). For a transported variable $a$, this hypothesis is expressed as:

$\overrightarrow{Q_{a, t}}=-D_{a, t} \nabla A$

where $\overrightarrow{Q_{a, t}}$ is the turbulent flux of $a, D_{a, t}$ is the turbulent diffusivity and $A=<a>$ is the mean value of a.

Although this assumption is generally valid, some cases exist where turbulent transport behaves in a different way. Dispersion from a rooftop vent on a cube is one of them, as shown in (Rossi et al., 2010) and (Gousseau et al., 2011b). Rossi et al. (2010) performed Direct Numerical Simulation of scalar dispersion around a cubic obstacle in a uniform air stream at Reynolds number $\operatorname{Re}=5000$. Downstream of the cube, the so-called counter-gradient (CG) mechanism was observed in the streamwise direction: the turbulent mass flux was directed backwards, from the low to high levels of concentration, in contradiction with Eq. 1. This phenomenon was also pointed out by Gousseau et al. (2011b), who used LES to show that this CG mechanism is also present in the case of turbulent inflow at higher Reynolds numbers, also when the location of the pollutant source is higher (half the building height above the roof).

CG turbulent scalar transport has also been reported for other configurations, for example in the case of a ground-level line source downstream of a wall-mounted 2D square obstacle (Vinçont et al., 2000), a ground-level line source in a street canyon (Simoëns and Wallace, 2008), a line source in a turbulent boundary layer (Raupach et al., 1983; Lavertu and Mydlarski, 2005), or a stratified shear flow (Meroney, 1976).

These examples from literature show that the concentration and velocity statistics can provide physical insight into the turbulent mass transport. However, to the best of the authors' knowledge, detailed analysis of concentration and velocity unsteady statistics for the case of an isolated building have not yet been published. The present study provides such an analysis, based on LES. As opposed to our previous paper (Gousseau et al. 2011b), a closer look at the concentration and 
velocity statistics is provided here, in order to better understand the CG mechanism of mass transport in the streamwise direction and in particular which instantaneous events lead on average to this phenomenon. The configuration under study is briefly described in the next section; it is based on wind-tunnel experiments ( $\mathrm{Li}$ and Meroney, 1983a, 1983b) whose concentration measurements are used to validate our numerical results (Section 3). In section 4, the concentration and velocity statistics at three monitoring points are presented and analyzed. Then, an attempt to relate these results to the turbulent flow patterns around the building is made (Section 5), after which conclusions are provided.

\section{Computational model}

\subsection{Domain, grid and boundary conditions}

The Ansys/Fluent 12 CFD code has been used to simulate dispersion around a cubical building model of side $H=0.05 \mathrm{~m}$ immersed in a turbulent atmospheric boundary layer (ABL). The mean velocity profile is a power law with exponent 0.19 . The aerodynamic roughness length $z_{0}=7.5 \times 10^{-5} \mathrm{~m}$. The longitudinal turbulence intensity of the approaching flow is equal to $11.8 \%$ at building height and to $15.2 \%$ at $0.015 \mathrm{~m}$ from the ground. Wind direction is perpendicular to the windward facade. At the center of the roof, helium is emitted by a $5 \mathrm{~mm}$ diameter circular exhaust with a low velocity ratio $M=0.19\left(M=W_{e} / U_{H}\right.$ where $W_{e}$ is the vertical exhaust velocity and $U_{H}$ is the mean velocity in the approaching ABL at building height). The Reynolds number based on $H$ and $U_{H}$ is equal to $1.1 \times 10^{4}$.

The computational domain and grid used in this study are the same as those in (Gousseau et al., 2011b). The domain has been conceived following the COST Action 732 (Franke et al., 2007, 2011) and AIJ (Tominaga et al., 2008b) guidelines. Its dimensions are equal to $26 H \times 11 H \times 6 H$ in the streamwise $(x)$, lateral $(y)$ and vertical $(z)$ directions, respectively. The grid was generated using the surface-extrusion procedure by van Hooff and Blocken (2010), yielding a grid with 1,480,754 hexahedral cells. Part of the grid on the building and ground surfaces is shown in Fig. 1; 32 cells are used for the building in the vertical direction and 25 in the longitudinal and lateral directions. The circular edge corresponding to the exhaust is discretized into 40 cells. Away from the building, the growth rate of the cell size has been kept below 1.1 to limit truncation and commutation errors (Franke et al., 2007). The simulation was performed on two other computational grids with 20 and 30 cells per building side. Neither the average nor the standard deviation of concentration was significantly affected by grid refinement.

Fig. 1 also shows the location of the points P1, P2 and P3; they will be used as monitoring points to analyze the statistics of concentration and velocity in the near-wake of the building. Their coordinates are summarized in Table 1.

The profiles of mean velocity, turbulent kinetic energy and turbulent dissipation rate are prescribed at the inlet of the domain, $5 \mathrm{H}$ upstream of the windward façade of the building. The vortex method (Sergent, 2002) is used to generate a turbulent inflow: a given number of vortices (here: 190) whose size and intensity depend on the local values of the prescribed variables are randomly generated and transported at the inlet plane to generate fluctuations on the mean velocity profiles. At the outlet of the domain, zero static pressure is imposed. Symmetry boundary conditions are used at the top and sides of the domain. The building and ground surfaces are defined as no-slip walls. No particular treatment has been applied to the ground surface to take into account its roughness but the length of the domain upstream of the cube is short enough to limit horizontal inhomogeneity affecting the inlet profiles (Blocken et al., 2007a, 2007b). The exhaust face is a velocity inlet injecting pure helium in the domain, with a constant exhaust rate $Q_{e}\left[\mathrm{~kg} . \mathrm{s}^{-1}\right]$. 


\subsection{LES modeling}

In the remainder of the paper, the Reynolds decomposition is used for all variables; for example $a$ is decomposed into its time-average component $A=\langle a\rangle$ and its fluctuation $a$ ' such that $a=A+a$ '. Furthermore, in what follows, the overbar is used to symbolize the spatial-filtering operator. Note that it will be used only in this section and will be omitted in the remaining of the paper.

LES is used with the dynamic Smagorinsky subgrid-scale (SGS) model (Smagorinsky, 1963; Germano et al., 1991; Lilly, 1992). The SGS Reynolds stresses $\tau_{i j}$ are computed based on the SGS viscosity $v_{S G S}$ and the filtered rate of strain $\bar{S}_{i j}=\left(\partial \bar{u}_{i} / \partial x_{j}+\partial \bar{u}_{j} / \partial x_{i}\right) / 2$, where $u_{i}$ is the component of the velocity vector in the direction $i$ :

$$
\tau_{i j}-\frac{1}{3} \tau_{k k} \delta_{i j}=-2 v_{S G S} \bar{S}_{i j}
$$

The SGS viscosity is computed following:

$$
v_{S G S}=L_{S G S}^{2} \bar{S}
$$

where $\bar{S}=\left(2 \bar{S}_{i j} \bar{S}_{i j}\right)^{1 / 2}, L_{S G S}=\min \left(\kappa d, C_{s} V_{c}^{1 / 3}\right)$ is the SGS mixing length, with $\kappa$ the von Karman constant, $d$ the distance to the closest wall, $V_{c}$ the volume of the computational cell and $C_{s}$ the Smagorinsky coefficient evaluated at each time step, based on the smallest resolved scales of motion. To avoid numerical instabilities, its value is clipped to the range $[0 ; 0.23]$.

In the filtered dispersion equation, the instantaneous SGS mass flux $\overrightarrow{q_{S G S}}$ is assumed to be proportional to the gradient of resolved concentration. The $i$-th component of this vector $(i=1,2,3)$ is given by:

$q_{S G S, i}=\overline{u_{i} c}-\overline{u_{i}} \bar{c}=-D_{S G S} \frac{\partial \bar{c}}{\partial x_{i}}$

where $c$ is the instantaneous concentration $\left[\mathrm{kg} \cdot \mathrm{m}^{-3}\right]$ and $D_{S G S}$ is the SGS mass diffusivity, linked to $v_{S G S}$ by:

$$
S c_{S G S}=\frac{v_{S G S}}{D_{S G S}}
$$

where $S c_{S G S}$ is the SGS Schmidt number, which is computed dynamically here (Moin et al., 1991).

The total turbulent mass flux $\overrightarrow{Q_{t}}$ is defined in the LES framework as the sum of the flux due to the resolved turbulent fluctuations and the mean SGS mass flux (Porté-Agel, 2004):

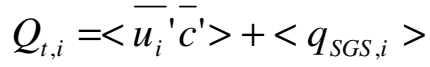

Reference concentration $\left(C_{0}\right)$ and flux $\left(Q_{0}\right)$ are used to make the variables non-dimensional. These quantities are defined by:

$$
\begin{aligned}
& C_{0}=\frac{Q_{e}}{H^{2} U_{H}} \\
& Q_{0}=C_{0} \times U_{H}
\end{aligned}
$$

Discretization of the filtered momentum equation is performed with a second-order accurate bounded central-differencing scheme. A second-order scheme is used for the spatial derivatives of the other equations (energy, concentration). Pressure interpolation is second order. The non-iterative time advancement scheme is used for the unsteady solver, with the fractional step method for pressure-velocity coupling (Kim and Moin, 1985). One single outer iteration is performed per time step, allowing reduction of the computational time needed for the simulation. A fixed time step 
$\Delta t^{*}=0.066$ in non-dimensional time units $\left(\Delta t^{*}=\Delta t \times U_{H} / H\right.$, where $\Delta t$ is the physical time step) has been set. After an initialization period, which allows losing the dependence on the non-physical initial state (which is here the solution of a preceding RANS simulation), averaging is performed during $t^{*}=1,584$. The data at the monitoring points are stored at each of these 24,000 time steps. In a previous study (Gousseau et al., 2011b), these settings were shown to accurately reproduce the mean concentration fields on the roof and in the wake of the cube.

\section{Mean concentration and turbulent mass flux}

The profiles of the non-dimensional concentration coefficient $\left(K=C / C_{0}\right)$ and the nondimensional standard deviation of concentration $\left(c_{r m s} / C_{l G}=\left(<c^{, 2}>\right)^{1 / 2} / C_{l G}\right)$ obtained with LES along three vertical lines $(x / H=1 ; 3 ; 5)$ are compared to the wind-tunnel measurements in Fig. 2 . The standard deviation of concentration is normalized by the mean ground concentration value at $x / H=1$ and $y / H=0\left(C_{l G}\right)$. Along these three lines, a good agreement is obtained for $K$ (Fig. 2a). Close to the building, at $x / H=1$, the LES results over-estimate the concentration fluctuations (Fig. 2b). Along the two other lines, there is a very close agreement.

With LES, the contribution of the non-resolved scales to the turbulent flux is often neglected (e.g. Tominaga and Stathopoulos, 2010; Gousseau et al., 2011b). Fig. 3 shows that with the grid resolution and SGS modeling used here, the SGS contribution to the total turbulent mass flux $\left(<q_{S G S, i}>=Q_{S G S, i}\right.$ in Eq. 6) is indeed negligible: the magnitude of $\overrightarrow{Q_{S G S}}$ is several orders of magnitude smaller than the one of $\vec{Q}_{t}$. However, note that Eq. 6 is used as a definition of the turbulent mass flux in the results presented hereafter, and the SGS contribution is included.

Contours of the different turbulent mass flux components are depicted in Fig. 4. In this figure, the isolines $\partial C / \partial x_{i}=0$ in the corresponding directions are also shown (dashed lines) and, in circles, the sign of $\partial C / \partial x_{i}$ for each zone delimited by the dashed line. As far as the vertical and lateral components of the turbulent flux $\left(Q_{t, z}\right.$ and $\left.Q_{t, y}\right)$ are concerned, the color contours in Figs. $4 \mathrm{c}$ and $4 \mathrm{~d}$ show that turbulent mass transport operates as a diffusion mechanism directed from the high towards the low concentration values, i.e. from the centerline of the plume to its outer edges. In the streamwise direction, however, the mechanism is different. In the horizontal plane $z / H=1.25$ for example, and more generally in the large region above the roof level colored in blue/light gray in Fig. 4a, the streamwise turbulent mass flux is negative, i.e. directed towards the high levels of $K$. In this region where the turbulent mass flux and the mean concentration gradient are of the same sign, the CG mechanism of turbulent mass transport is present. Another CG zone is present in the nearwake of the building (where P3 is located) where both $Q_{t, x}$ and $\partial C / \partial x$ are positive. Note that the monitoring points $\mathrm{P} 1, \mathrm{P} 2$ and $\mathrm{P} 3$ have been selected in such a way that they are located in different characteristic zones of the $\overrightarrow{Q_{t}}$ field.

\section{Concentration and velocity statistics at the monitoring points}

The resolved concentration $(c)$ and velocity components $(u, v, w)$ have been recorded at the three monitoring points at each of the 24,000 time steps of the simulation. Various descriptive statistics of these variables are reported in Tables 2 to 5 for these three points. The subscript 'rms' indicates the standard deviation; $S_{a}$ and $K_{a}$ correspond to the skewness and kurtosis of the variable $a$, respectively; $a^{\prime}{ }_{\min }$ and $a^{\prime}{ }_{\max }$ stand for the minimum and maximum fluctuations of $a$. The sign of the local spatial derivative value of mean concentration is also included in Table 2 to verify that it 
corresponds to the sign of $\left\langle u^{\prime} c^{\prime}\right\rangle$ (CG mechanism) in the x-direction (Table 3) and to the opposite sign of $\left\langle v^{\prime} c^{\prime}\right\rangle$ and $\left\langle w^{\prime} c^{\prime}\right\rangle$ in the $\mathrm{y}$ - and z-direction, respectively (Tables 4 and 5).

For the four variables of interest, the range of the non-dimensional fluctuations $\left(a^{\prime}{ }_{k} / a_{r m s}\right.$, where $k$ is the sample number) has been divided into 50 equal intervals $I_{i}(i=1, \ldots, 50)$ and the frequency $f_{i}$ of occurrence of $a^{\prime}{ }_{k} / a_{r m s} \in I_{i}$ has been calculated following Eq. 9 to build the histogram of frequency distribution:

$f_{i}=\frac{n_{i}}{N} \quad(i=1, \ldots, 50)$

where $n_{i}$ is the number of samples such as $a^{\prime}{ }_{k} / a_{r m s} \in I_{i}$ and $N$ is the total number of samples.

The histograms for point P1 are shown in Fig. 5. The histogram of concentration fluctuations (Fig. 5a) has an exponential-like shape, which indicates that P1 is most of the time characterized by a low background concentration level and the occurrence of rare but extremely high peaks of concentration - also indicated by the high value of $K_{c}$, see Table 2 . Approximately $60 \%$ of the samples are of negative fluctuation and the average is raised by peaks of $c$ ' reaching up to 13 times the standard deviation. This asymmetry around the mean is quantified by the high skewness value. This shape of frequency distribution corresponds to measurements by Fackrell and Robins (1982) far from the ground in the case of an elevated point source and was attributed to the meandering motion of the plume caused by large turbulent eddies. Here, the largest turbulence scales are of the order of the cube size, larger than the size of the plume at P1, and tend to move the plume as a block, resulting in the high intermittency observed at this monitoring point.

The frequency distribution of $u^{\prime} / u_{r m s}$ shows negative skewness (Fig. 5b): among the samples, the majority is of positive fluctuation but some of them are characterized by a large negative $u$ '. The opposite holds for the vertical velocity fluctuations, whose frequency distribution is right-tailed (Fig. 5d). Considering that P1 lies in the vertical symmetry plane of the computational domain, it is logical that the frequency distribution of $v^{\prime} / v_{r m s}$ is symmetric with respect to its zero mean (Fig. 5c).

A similar approach can be used to analyze the statistics of the variables two by two. The bivariate histograms have been built for the three couples of variables $\left(c^{\prime} / c_{r m s} ; u_{i}^{\prime} / u_{i, r m s}\right)$. For example, for two variables $a$ and $b$, the range of the non-dimensional fluctuations has been divided into an arbitrary number of intervals (here: 20), say $I_{i}$ for $a^{\prime}{ }_{k} / a_{r m s}$ and $J_{j}$ for $b^{\prime}{ }_{k} / b_{r m s}$. For given $i$ and $j$, the frequency $f_{i, j}=f\left(I_{i}, J_{j}\right)$ is the ratio of the number of samples $n_{i, j}$ for which $a^{\prime}{ }_{k} / a_{r m s} \in I_{i}$ and simultaneously $b^{\prime}{ }_{k} / b_{r m s} \in J_{j}$ to the total number of samples $N$ :

$$
f_{i, j}=\frac{n_{i, j}}{N} \quad(i, j=1, \ldots, 20)
$$

Each of the four combinations of signs of $\left(c^{\prime} / c_{r m s} ; u_{i}^{\prime} / u_{i, r m s}\right)$ is associated with a specific event of pollutant transport. Observing the bivariate histograms gives therefore an indication of which events are the most frequent among the samples and/or contribute the most to the turbulent flux. This socalled quadrant analysis was first introduced for momentum transfer (Shaw et al., 1983) but is also widely used in the case of scalar dispersion (e.g. Chen, 1990; Katul et al. 1997; Cheng et al., 2011). The definitions of the quadrants are shown in Table 6, together with the name given to the corresponding event in the vertical direction, for which quadrant analysis is often used. Note that this nomenclature can also be used here for the lateral direction, considering the symmetry of our problem. The frequency of occurrence of a given quadrant $\mathrm{Q}_{\mathrm{m}}$ is equal to the sum of the frequencies of the intervals which compose $\mathrm{Q}_{\mathrm{m}}$. This frequency multiplied by the average of $u_{i}$ ' $c$ ' on $\mathrm{Q}_{\mathrm{m}}$ $\left(\left\langle u_{i}{ }^{\prime}{ }^{\prime}\right\rangle_{\mathrm{Q}}\right)$ gives the contribution of the quadrant $\mathrm{Q}_{\mathrm{m}}$ to the turbulent flux in the direction $i$.

The contours of $f_{i, j}$ in the planes $\left(c^{\prime} / c_{r m s} ; u_{i}{ }^{\prime} / u_{i, r m s}\right)$ for P1 are shown in Fig. 6 . In the streamwise direction (Fig. 6a), the most frequent situation among the samples is simultaneously $u^{\prime}>0$ and $c^{\prime}<0$ (Q4): $46 \%$ of the samples are in this zone. Nevertheless, the most important contribution to the total turbulent flux is due to Q2, for which the frequency (27\%) is lower than for 
Q4 but for which the individual contributions $u^{\prime} c^{\prime}$ are on average higher in magnitude. The contributions of Q1 and Q3 are minor in this case, both in terms of frequency and magnitude. The dominant contributions of $\mathrm{Q} 2$ and $\mathrm{Q} 4$, where $u$ ' and $c$ ' are of opposite signs, result on average in a negative turbulent flux $\left\langle u^{\prime} c^{\prime}\right\rangle$. Concerning the lateral direction, the frequency distribution of $\left(c^{\prime} / c_{r m s} ; v^{\prime} / v_{r m s}\right)$ is approximately symmetrical with respect to the axis $v^{\prime}=0$, leading to a zero turbulent mass flux in the lateral direction (Fig. 6b). Concerning the vertical direction, sweeps (Q3) are the most frequent events of vertical mass transfer at P1 (Fig. 6c); they correspond to downward motions of fresh air. However, the calculation of the contribution of each quadrant to $Q_{t, z}$ shows that the dominant contribution is made by ejections (Q1), which occur less often but are more intense.

One step further in the statistical analysis is to analyze the variables three by three, following the octant analysis by Vinçont et al. (2000). The repartition of the samples among the eight octants of the three-dimensional space $\left(c^{\prime} / c_{r m s} ; u^{\prime} / u_{r m s} ; w^{\prime} / w_{r m s}\right)$ shows that the Q2 events in the X-direction coincide with the Q1 events in the z-direction (not shown here). Hence, the largest contribution to both $Q_{t, x}$ and $Q_{t, z}$ is due to samples for which $\left(c^{\prime}>0 ; u^{\prime}<0 ; w^{\prime}>0\right)$ i.e. upwards movement of polluted air coming from the plume centerline with lower streamwise velocity. The most frequent octant and second largest contribution to $Q_{t, x}$ and $Q_{t, z}$ corresponds to $\left(c^{\prime}<0 ; u^{\prime}>0 ; w^{\prime}<0\right)$ : fresh air entrained from the top of the plume with relatively high streamwise velocity and downward motion.

Fig. 7a shows the frequency distribution of $c^{\prime} / c_{r m s}$ for $\mathrm{P} 2$. The trend is similar as for P1, with even higher values of skewness and kurtosis (see Table 2), because of the off-center position of the sampling point at which the plume intermittency is higher (Fackrell and Robins, 1982).

Approximately $65 \%$ of the samples have concentration values between zero and one third of the mean concentration value at this point. The velocity fluctuations in the $\mathrm{x}$ - and $\mathrm{z}$-directions also have similar frequency distributions as those at $\mathrm{P} 1$, with a negative and positive skewness, respectively. The main difference with point $\mathrm{P} 1$ is the asymmetry of the histogram of $v^{\prime} / v_{r m s}$, quantified by the non-zero skewness $S_{v}=0.52$. This feature is due to the position of P2 out of the symmetry plane of the geometry.

The bivariate histogram of $\left(c^{\prime} / c_{r m s} ; v^{\prime} / v_{r m s}\right)$ is similar in shape to the one of $\left(c^{\prime} / c_{r m s} ; w^{\prime} / w_{r m s}\right)$ (Figs. 8b,c): a large majority of the samples belongs to Q3 and the main contribution to the mass flux is due to intense ejections corresponding to quadrant Q1. Hence, both $Q_{t, y}$ and $Q_{t, z}$ are positive at P2. Concerning the streamwise direction, the bivariate histogram (Fig. 8a) is similar in shape to the one at P1 and the octant analysis (not shown here) indicates that intense Q2 events in the Xdirection coincide with Q1 events in the $y$ - and z-directions.

For P3, the frequency distribution of concentration fluctuations is different (Fig. 9a). Its shape resembles a log-normal distribution, similar to what can be observed close to the ground in the case of an elevated point source in a turbulent boundary layer (Fackrell and Robins, 1982). Note that at this location, in the near wake of the building, the intensity of the concentration fluctuations $c_{r m s} / C$ is weaker in comparison with $\mathrm{P} 1$ and $\mathrm{P} 2$ (Table 2). Noticeably, the three velocity components have a similar, symmetric distribution with a skewness value close to zero (Figs. 9b,c,d).

Despite the symmetry of the velocity frequency distributions, the bivariate analysis shows that simultaneity of concentration and velocity fluctuations of particular signs lead on average to non-zero mass fluxes. The main contribution to streamwise mass transfer at P3 is due to Q1 and Q3 quadrants, the former being the most intense events and the latter the most frequent (Fig. 10a). It explains the positive $Q_{t, x}$ at this location. The bivariate frequency distribution of $\left(c^{\prime} / c_{r m s} ; v^{\prime} / v_{r m s}\right)$ is symmetric around the abscissa axis, resulting in a negligible $Q_{t, y}$ in comparison with $Q_{0}$ (Fig. 10b). Vertically, mass transfer is governed by frequent inward (Q4) and intense outward (Q2) interactions (Fig. 10c).

The octant analysis shows the simultaneity of Q1 events in the $\mathrm{x}$ - and Q2 events in the $\mathrm{z}$ direction. The event $\left(c^{\prime}<0 ; u^{\prime}<0 ; w^{\prime}>0\right)$ is the most frequent at $\mathrm{P} 3$, corresponding to motions of fresh air originating from zones closer to the ground. The other dominant contribution to the mass 
flux is due to the events $\left(c^{\prime}>0 ; u^{\prime}>0 ; w^{\prime}<0\right)$ which are less frequent but more intense. They correspond to movements of high streamwise velocity polluted air directed downwards.

\section{Further analysis and discussion}

The contours of streamwise $\left(R_{u u}\right)$ and vertical $\left(R_{w w}\right)$ two-point correlation coefficients in the plane $y / H=0$ are shown in Fig. 11. $R_{u_{i} u_{j}}$ is defined by:

$$
R_{u_{i} u_{j}}\left(\vec{x}, \vec{x}_{r e f}\right)=\frac{\left\langle u_{i}{ }^{\prime}(\vec{x}) u_{j}{ }^{\prime}\left(\vec{x}_{r e f}\right)\right\rangle}{u_{i, r m s}(\vec{x}) u_{j, r m s}\left(\vec{x}_{r e f}\right)}
$$

The reference point $\mathrm{P}_{\text {ref }}$ is taken at $x_{\text {ref }} / H=1.020, y_{\text {ref }} / H=0$ and $z_{\text {ref }} / H=1.245$. The computation of these coefficients is made by user programming (User-Defined Function) which allows accessing the data at cell centers; this is the reason why $\mathrm{P}_{\text {ref }}$ is not located exactly at $\mathrm{P} 1$, but very close to it. By definition, the correlation coefficients take the value 1 at $\mathrm{P}_{\text {ref }}$, as can be seen in Fig. 11. The negative values of $R_{u u}$ in the wake of the cube indicate the backflow characteristic of the recirculation zone (Fig. 11a). In Fig. 11b, one can notice the alternation of zones with negative (blue/light gray) and positive (red/dark gray) correlation coefficient $R_{w w}$ in the shear layer, starting from the top of the windward facade. This feature can be interpreted as an indication of the presence of large vortical structures in this zone (Savory et al., 2011), generated at the front corner and transported downstream with an increasing length scale. On can infer the occurrence of a similar flow phenomenon on the sides of the cube (not shown in figure), from which shear layers develop as well.

Experimental investigation of the flow around a circular cylinder (Ong and Wallace, 1996) shows that the vortex shedding which takes place in the wake of the cylinder acts on the skewness of the velocity. For the streamwise component, the skewness is low and positive at the center of the wake and turns to large negative values at its outer edges. Concerning the transverse velocity, if $y=0$ is the plane aligned with the flow direction and corresponding to the symmetry plane of the z-axis cylinder, the skewness tends to be positive for $y>0$ and negative for $y<0$. Although the flow around a wall-mounted cube is fully three-dimensional and more complex (see e.g. (Wang et al., 2009) for a description of the flow around wall-mounted finite-length square cylinders), the link between vortical structures and velocity skewness appears to be similar. Fig. 12b shows the contours of $S_{u}$ in the horizontal plane $z / H=0.75$. In the wake of the building, the trend is the same as described above: $S_{u}$ is low and positive at the center of the wake and negative and high in magnitude at the outer edges, because of the presence of vortical structures in the side shear layers. The analogy with the circular cylinder holds also for $S_{v}$ which is positive for $y>0$ and negative for $y<0$ (Fig. 12d). The plane $z / H=1.25$ is shown and the trend is the same for $z / H \leq 1$. What occurs above the building is similar to what has been described above for the horizontal planes, as can be seen in Figs. 12a,c. However, the presence of the ground wall breaks the symmetry: large negative (resp. positive) values of $S_{u}$ (resp. $S_{w}$ ) are found in the shear layer above the building containing P1 and P2 but in the wake - where the large recirculation operates but only small-scale vortices are present ( $\mathrm{Li}$ and Meroney, 1983b) - the trend is less marked and the skewness values are low in magnitude.

In the shear layers, the peaks of velocity fluctuations - positive or negative, depending on the location and the velocity component - created by the instantaneous flow patterns often coincide with a preferred sign of concentration fluctuation. This was shown to be true at P1 and P2 and can reasonably be generalized to the roof and side shear layers. At these two points, for example, lowspeed motions of polluted air originating from the center of the plume could be identified. They are rare but very intense and constitute the main contribution to the turbulent mass flux in the streamwise and vertical directions (and also laterally if an off-center point is considered). 
Behind the building and below $z / H=1$, in the near-wake recirculation zone, no large vortical structures are present, which seems to be the reason why no particular trend was observed for the skewness of the three velocity components. However, the bivariate analysis at P3 showed that, at this location too, the peaks of concentration fluctuations are likely to be associated with a preferred sign of velocity fluctuations, and generate a non-zero turbulent mass flux. At P3, intense motions of polluted air coming from the center of the plume with high streamwise velocity and frequent movements of fresh air coming from zones close to the ground were observed. Note that these results have been confirmed by the observation of the statistics at seven additional monitoring points located in various regions of the flow, which have not been reported due to space limitations.

\section{Summary and conclusions}

Wind-induced pollutant dispersion from a rooftop vent on top of a cubical building model has been simulated with Large-Eddy Simulation and the dynamic Smagorinsky SGS model. The unsteady statistics of concentration and velocity at three monitoring points located in the near-wake of the building have been collected for a sufficiently long period for a detailed analysis of turbulent mass transport. Mono- and bivariate histograms of concentration and velocity fluctuations at these three points have been built to detect the events contributing to turbulent mass transport. Octant analysis has also been performed and provided valuable insights (although no plots were shown here). A generalization of these results to the near-wake of the building has been proposed.

First, by comparing our numerical results with the wind-tunnel measurements of mean value and standard deviation of concentration, the good accuracy of the present LES modeling in predicting concentration statistics has been demonstrated for the case of dispersion around an isolated building. Moreover, the mean SGS mass flux has been shown to be negligible compared to the total turbulent mass flux with the grid resolution and SGS modeling used here.

Due to the presence of large-scale vortices around the cube, the plume exhibits a meandering motion, as can be seen in the frequency distribution of the concentration fluctuations: it has approximately an exponential shape in the wake of the building above roof level (points P1 and P2) and a log-normal shape below roof level (P3). In both cases, the skewness and kurtosis values are high, indicating the existence of a relatively low background concentration punctuated by rare but extremely high peaks.

The frequency distributions of the velocity fluctuations are also affected by the turbulent flow patterns. In the absence of large vortical structures (P3), the frequency distributions of $u^{\prime}, v^{\prime}$ and $w^{\prime}$ are symmetric, with skewness values close to zero, whereas in the shear layers developing from the roof and side walls of the buildings (P1 and P2) the large vortical structures are responsible for peaks of velocity fluctuations quantified by the non-zero skewness values of the frequency distributions.

In summary, the frequency distributions of both concentration and velocity fluctuations are affected by the same flow phenomenon. As a consequence, it seems logical to observe a direct link between $u_{i}$ ' and $c^{\prime}$ ' events. The bivariate analysis showed indeed that for a given sign of $c$ ' there is a preferred sign of $u_{i}$ ' which is more likely to occur. In the streamwise direction, it was shown at P1 and $\mathrm{P} 2$ that $c^{\prime}$ ' and $u$ ' most of the time have opposite signs, leading on average to a negative turbulent mass flux $Q_{t, x}$ and explaining the CG mechanism in this zone.

It has been shown that specific unsteady events govern turbulent mass transport, which explains the failure of the first-order closure model (Eq. 1). If used, this model should be adapted to reproduce the CG mechanism of turbulent mass transport - for example by taking out the minus sign from the right-hand side of Eq. 1 - and to take into account the flow anisotropy, by use of a diffusivity vector. 


\section{References}

Balczó, M., Gromke, C., Ruck, B., 2009. Numerical modeling of flow and pollutant dispersion in street canyons with tree planting. Meteorologische Zeitschrift 18, 197-206.

Blocken, B., Stathopoulos, T., Carmeliet, J., 2007a. CFD simulation of the atmospheric boundary layer: wall function problems. Atmospheric Environment 41, 238-252.

Blocken, B., Carmeliet, J., Stathopoulos, T., 2007b. CFD evaluation of the wind speed conditions in passages between buildings - effect of wall-function roughness modifications on the atmospheric boundary layer flow. Journal of Wind Engineering and Industrial Aerodynamics 95, 941-962.

Blocken, B., Stathopoulos, T., Saathoff, P., Wang, X., 2008. Numerical evaluation of pollutant dispersion in the built environment: comparisons between models and experiments. Journal of Wind Engineering and Industrial Aerodynamics 96, 1817-1831.

Chen, F., 1990. Turbulent characteristics over a rough natural surface. Part I: Turbulent structures. BoundaryLayer Meteorology 52, 151-175.

Cheng, W.C., Liu, C.H., 2011. Large-Eddy Simulation of flow and pollutant transports in and above twodimensional idealized street canyons. Boundary-Layer Meteorology 139, 411-437.

Fackrell, J.E., Robins, A.G., 1982. Concentration fluctuations and fluxes in plumes from point sources in a turbulent boundary layer. Journal of Fluid Mechanics 117, 1-26.

Fluent 6.3 User's Guide, Fluent Inc., Lebanon, 2006

Franke, J., Hellsten, A., Schlünzen, H., Carissimo, B., 2007. Best practice guideline for the CFD simulation of flows in the urban environment. COST Action 732.

Franke, J., Hellsten, A., Schlünzen, H., Carissimo, B., 2011. The COST 732 best practice guideline for CFD simulation of flows in the urban environment - A summary. International Journal of Environment and Pollution 44, 419-427.

Germano, M., Piomelli, U., Moin, P., Cabot, W.H., 1991. A dynamic subgrid-scale eddy viscosity model. Physics of Fluids A 3, 1760-1765.

Gousseau, P., Blocken, B., Stathopoulos, T., van Heijst, G.J.F., 2011a. CFD simulation of near-field pollutant dispersion on a high-resolution grid: a case study by LES and RANS for a building group in downtown Montreal. Atmospheric Environment 45, 428-438.

Gousseau, P., Blocken, B., van Heijst, G.J.F., 2011b. CFD simulation of pollutant dispersion around isolated buildings: On the role of convective and turbulent mass fluxes in the prediction accuracy. Journal of Hazardous Materials 194, 422-434.

Gromke, C., Buccolieri, R., Di Sabatino, S., Ruck B., 2008. Dispersion study in a street canyon with tree planting by means of wind tunnel and numerical investigations - Evaluation of CFD data with experimental data. Atmospheric Environment 42, 8640-8650.

Hanna, S.R., Brown, M.J., Camelli, F.E., Chan, S.T., Coirier, W.J., Hansen, O.R., Huber, A.H., Kim S., Reynolds R.M., 2006. Detailed simulations of atmospheric flow and dispersion in downtown Manhattan. An application of five computational fluid dynamics models. Bulletin of the American Meteorological Society 87, 1713-1726.

Katul, G., Kuhn, G., Schieldge, J., Hsieh, C.-I., 1997. The ejection-sweep character of scalar fluxes in the unstable surface layer. Boundary-Layer Meteorology 83, 1-26.

Kim, J., Moin, P., 1985. Application of a fractional step method to incompressible Navier-Stokes equations. Journal of Computational Physics 59, 308-323.

Lavertu, R.A., Mydlarski, L., 2005. Scalar mixing from a concentrated source in turbulent channel flow. Journal of Fluid Mechanics 528, 135-172.

Li, W.-W., Meroney, R.N., 1983a. Gas dispersion near a cubical model building - Part I. Mean concentration measurements. Journal of Wind Engineering and Industrial Aerodynamics 12, 15-33.

Li, W.-W., Meroney, R.N., 1983b. Gas dispersion near a cubical model building - Part II. Concentration fluctuation measurements. Journal of Wind Engineering and Industrial Aerodynamics 12, 35-47.

Lilly, D.K., 1992. A proposed modification of the Germano subgrid-scale closure method. Physics of Fluids A $4,633-635$.

Meroney, R.N., 1976. An algebraic stress model for stratified turbulent shear flows. Computers and Fluids 4, 93-107. 
Meroney, R.N., Leitl, B.M., Rafailidis, S., Schatzmann, M., 1999. Wind-tunnel and numerical modeling of flow and dispersion about several building shapes. Journal of Wind Engineering and Industrial Aerodynamics 81, 333-345.

Meroney, R.N., 2004. Wind tunnel and numerical simulation of pollution dispersion: a hybrid approach. Working paper, Croucher Advanced Study Insitute on Wind Tunnel Modeling, Hong Kong University of Science and Technology, 6-10 December, 2004, 60 pp.

Moin, P., Squires, K., Cabot, W., Lee, S., 1991. A dynamic subgrid-scale model for compressible turbulence and scalar transport. Physics of Fluids A3-11, 2746-2757.

Murakami, S., 1993. Comparison of various turbulence models applied to a bluff body. Journal of Wind Engineering and Industrial Aerodynamics 46\&47, 21-36.

Ong, L., Wallace, J., 1996. The velocity field of the turbulent very near wake of a circular cylinder. Experiments in Fluids 20, 441-453.

Porté-Agel, F., 2004. A scale-dependent dynamic model for scalar transport in large-eddy simulations of the atmospheric boundary layer. Boundary-Layer Meteorology 112, 81-105.

Raupach, M.R., Legg, B.J., 1983. Turbulent dispersion from an elevated line source: measurements of windconcentration moments and budgets. Journal of Fluid Mechanics 136, 111-137.

Rodi, W., 1997. Comparison of LES and RANS calculations of the flow around bluff bodies. Journal of Wind Engineering and Industrial Aerodynamics 69-71, 55-75.

Rossi, R., Philips, D.A., Iaccarino, G., 2010. A numerical study of scalar dispersion downstream of a wallmounted cube using direct simulations and algebraic flux models. International Journal of Heat and Fluid Flow 31, 805-819.

Savory, E., Perret, L., Rivet, C., 2011. Modelling the flow regime in a simple urban-type street canyon. International workshop on physical modelling of flow and dispersion phenonema. August 2011, Hamburg.

Sergent, E., 2002. Vers une méthode de couplage entre la simulation des grandes échelles et les modèles statistiques. Thèse présentée devant l'Ecole Centrale de Lyon.

Shaw, R.H., Tavangar, J., Ward, D.P., 1983. Structure of the Reynolds stress in a canopy layer. Journal of Climate and Applied Meteorology 22, 1922-1931.

Simoëns, S., Wallace, J.M., 2008. The flow across a street canyon of variable width-Part 2: Scalar dispersion from a street level line source. Atmospheric Environment 42, 2489-2503.

Smagorinsky, J., 1963. General circulation experiments with the primitive equations. I. The basic experiment. Monthly Weather Review 91, 99-164.

Tominaga, Y., Murakami, S., Mochida, A., 1997. CFD prediction of gaseous diffusion around a cubic model using a dynamic mixed SGS model based on composite grid technique. Journal of Wind Engineering and Industrial Aerodynamics 67-68, 827-841.

Tominaga, Y., Stathopoulos, T., 2007. Turbulent Schmidt numbers for CFD analysis with various types of flowfield. Atmospheric Environment 41, 8091-8099.

Tominaga, Y., Mochida, A., Murakami, S., Sawaki, S., 2008a. Comparison of various revised k- $\varepsilon$ models and LES applied to flow around a high-rise building model with 1:1:2 shape placed within the surface boundary layer. Journal of Wind Engineering and Industrial Aerodynamics 96, 389-411.

Tominaga, Y., Mochida, A., Yoshie, R., Kataoka, H., Nozu, T., Yoshikawa, M., Shirasawa, T., 2008b. AIJ guidelines for practical applications of CFD to pedestrian wind environment around buildings. Journal of Wind Engineering and Industrial Aerodynamics 96, 1749-1761.

Tominaga, Y., Stathopoulos, T., 2010. Numerical simulation of dispersion around an isolated cubic building: model evaluation of RANS and LES. Build. Environ. 45, 2231-2239.

Tominaga, Y., Stathopoulos, T., 2011. CFD modeling of pollution dispersion in a street canyon: Comparison between LES and RANS. Journal of Wind Engineering and Industrial Aerodynamics 99, 340-348.

Vinçont, J.-Y., Simoëns, S., Ayrault, M., Wallace, J.M., 2000. Passive scalar dispersion in a turbulent boundary layer from a line source at the wall and downstream of an obstacle. Journal of Fluid Mechanics 424, 127-167.

van Hooff, T., Blocken, B., 2010. Coupled urban wind flow and indoor natural ventilation modelling on a high-resolution grid: a case study for the Amsterdam ArenA stadium. Environ. Modell. Softw. 25, 5165. 
Wang, H.F., Zhou, Y., 2009. The finite-length square cylinder near wake. Journal of Fluid Mechanics 638, 453-490. 


\section{Figures}
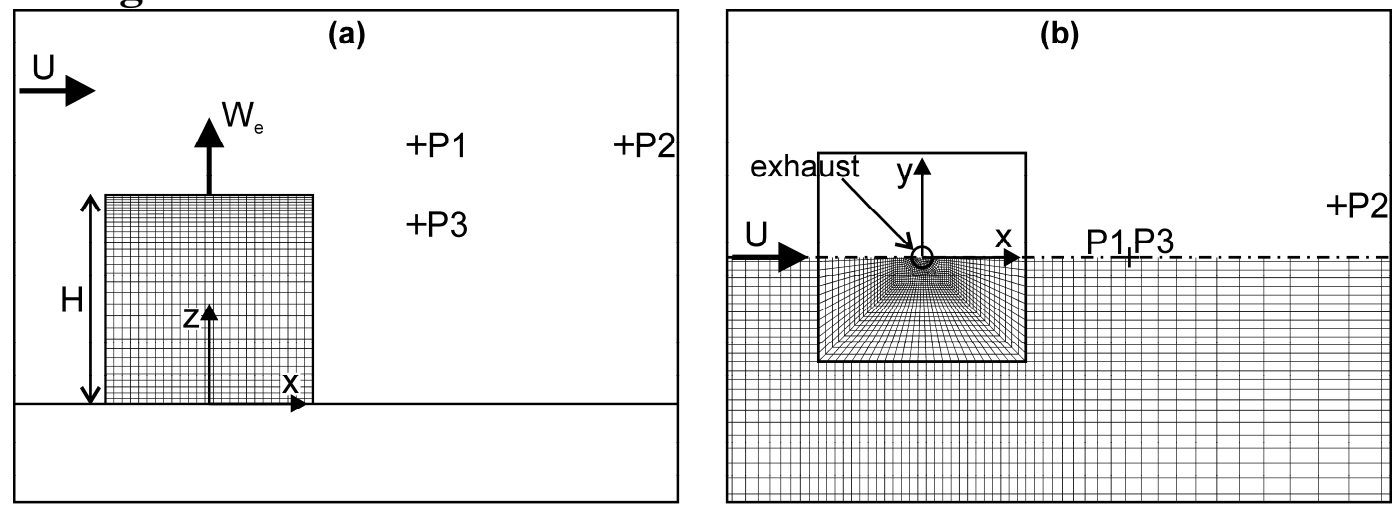

Figure 1. Side view (a) and top view (b) of the computational grid on the building and ground surfaces (total number of cells: 1,480,754). For readability, only part of the grid is shown in (b).
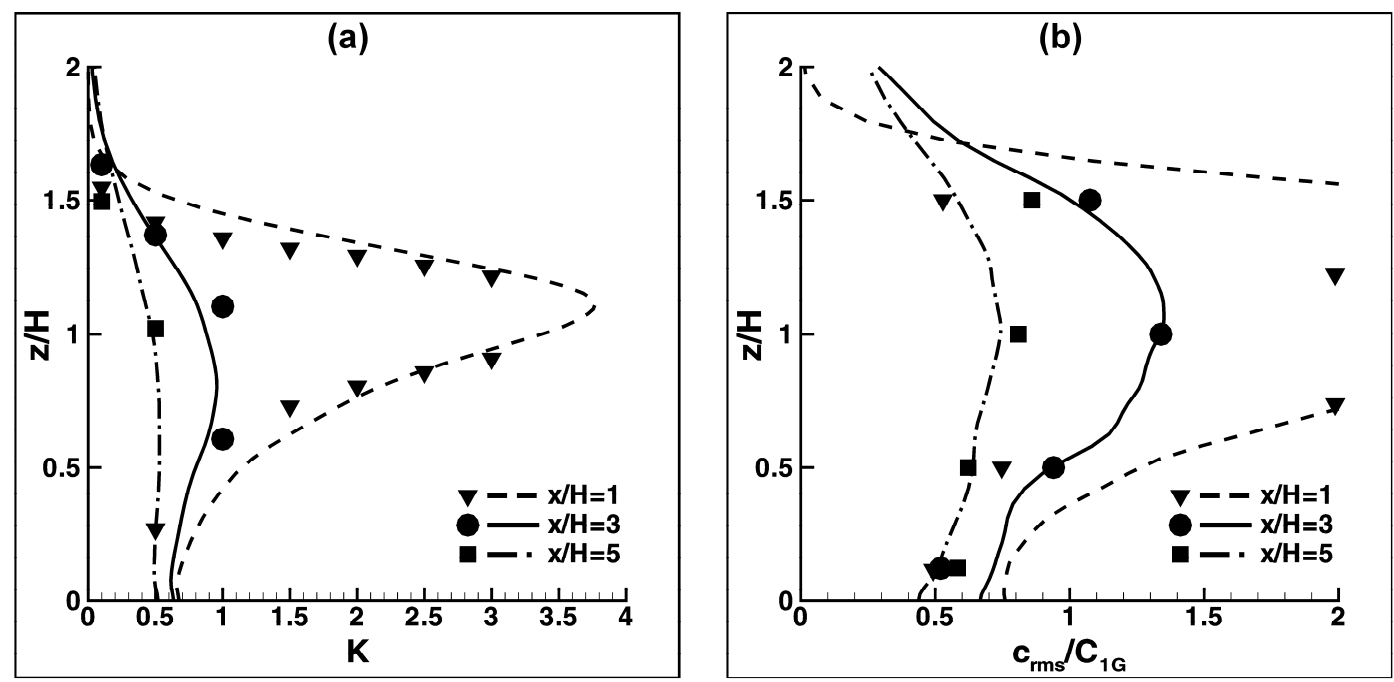

Figure 2. CFD validation: profiles of (a) non-dimensional concentration coefficient $K=C / C_{0}$ and (b) standard deviation of concentration normalized by $C_{l G}$ along three vertical lines in the plane $y / H=0$. Symbols: wind tunnel measurements (Li and Meroney, 1983a, 1983b); lines: LES in this study.
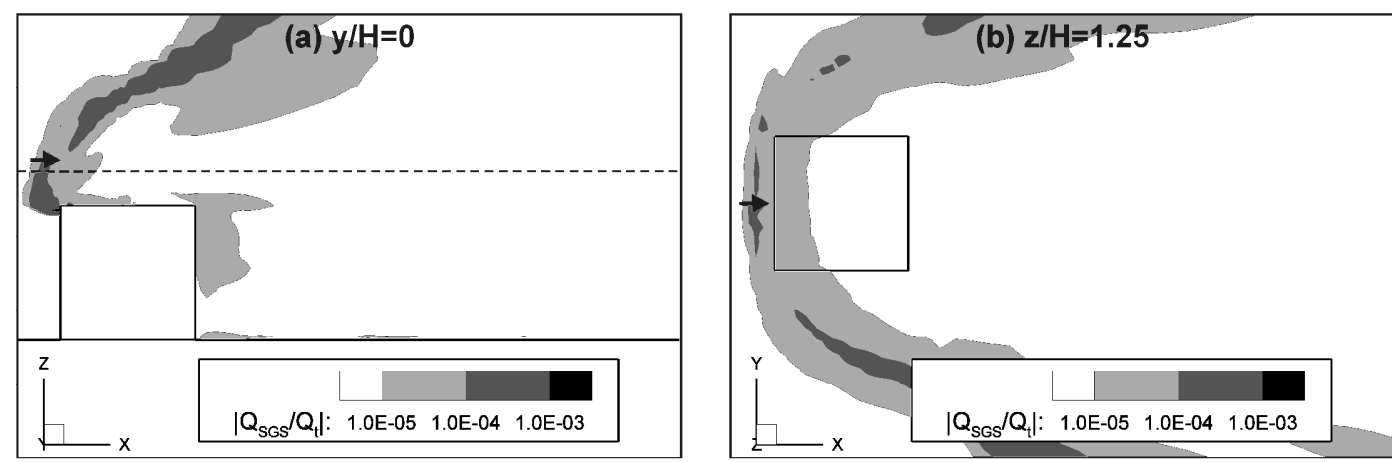

Figure 3. Relative contribution of the SGS mass flux to the total turbulent mass flux: contours of $\left|Q_{S G S} / Q_{t}\right|$ in the planes (a) $y / H=0$ and (b) $z / H=1.25$. In (a), the dashed line represents the position of the horizontal plane shown in (b). 

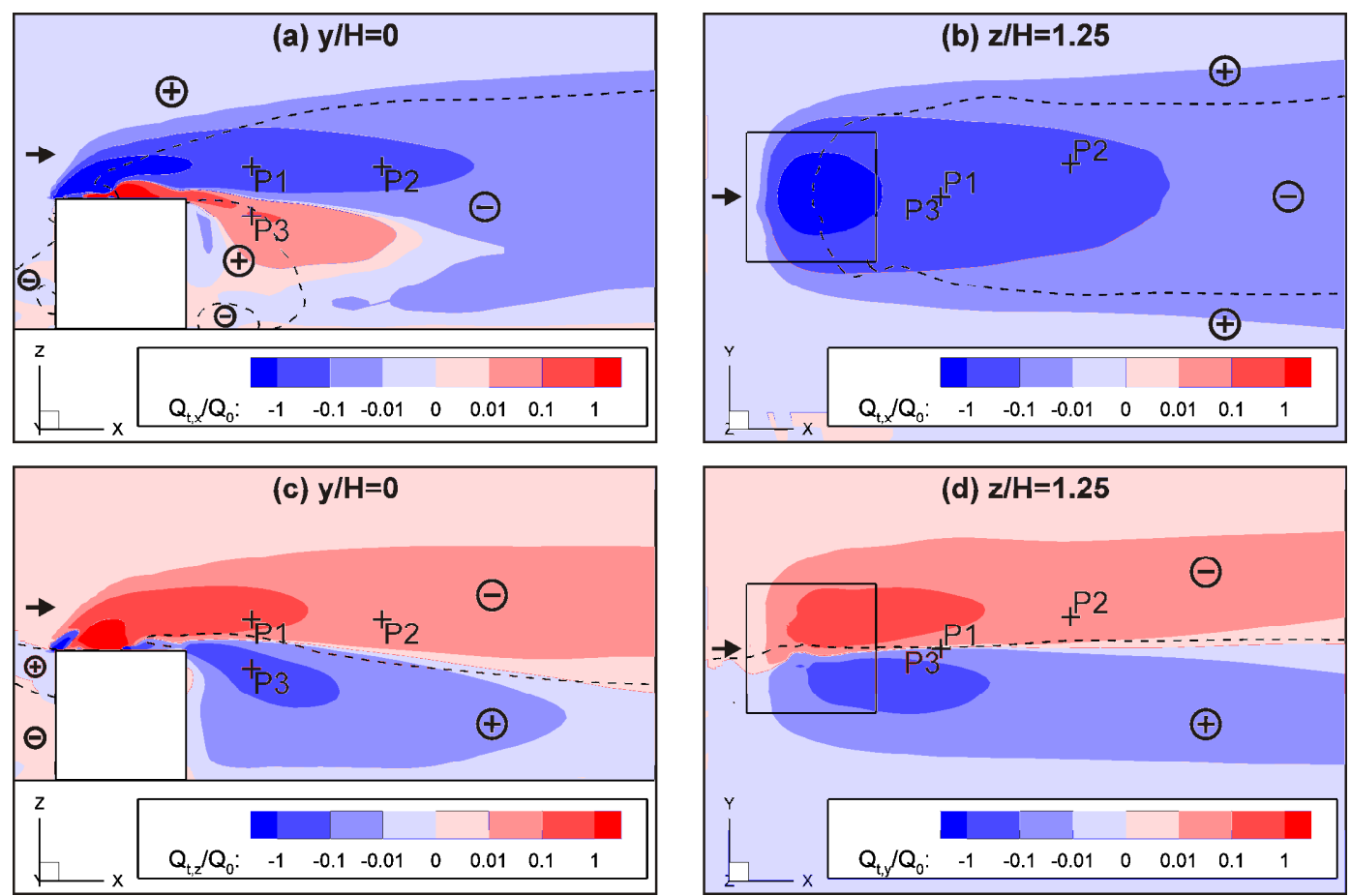

Figure 4. Contours of the (a,b) streamwise, (c) vertical, and (d) lateral components of the turbulent mass flux vector. The dashed lines represent the isolines $\partial C / \partial x_{i}=0$ in the corresponding direction: (a,b) $x_{i}=x$, (c) $x_{i}=z$, (d) $x_{i}=y$. On each side of the isoline, the sign of $\partial C / \partial x_{i}$ is indicated in circles (+: positive; -: negative). The CG mechanism of turbulent mass transport is characterized by $Q_{t, i}$ and $\partial C / \partial x_{i}$ of the same sign for a given direction. 

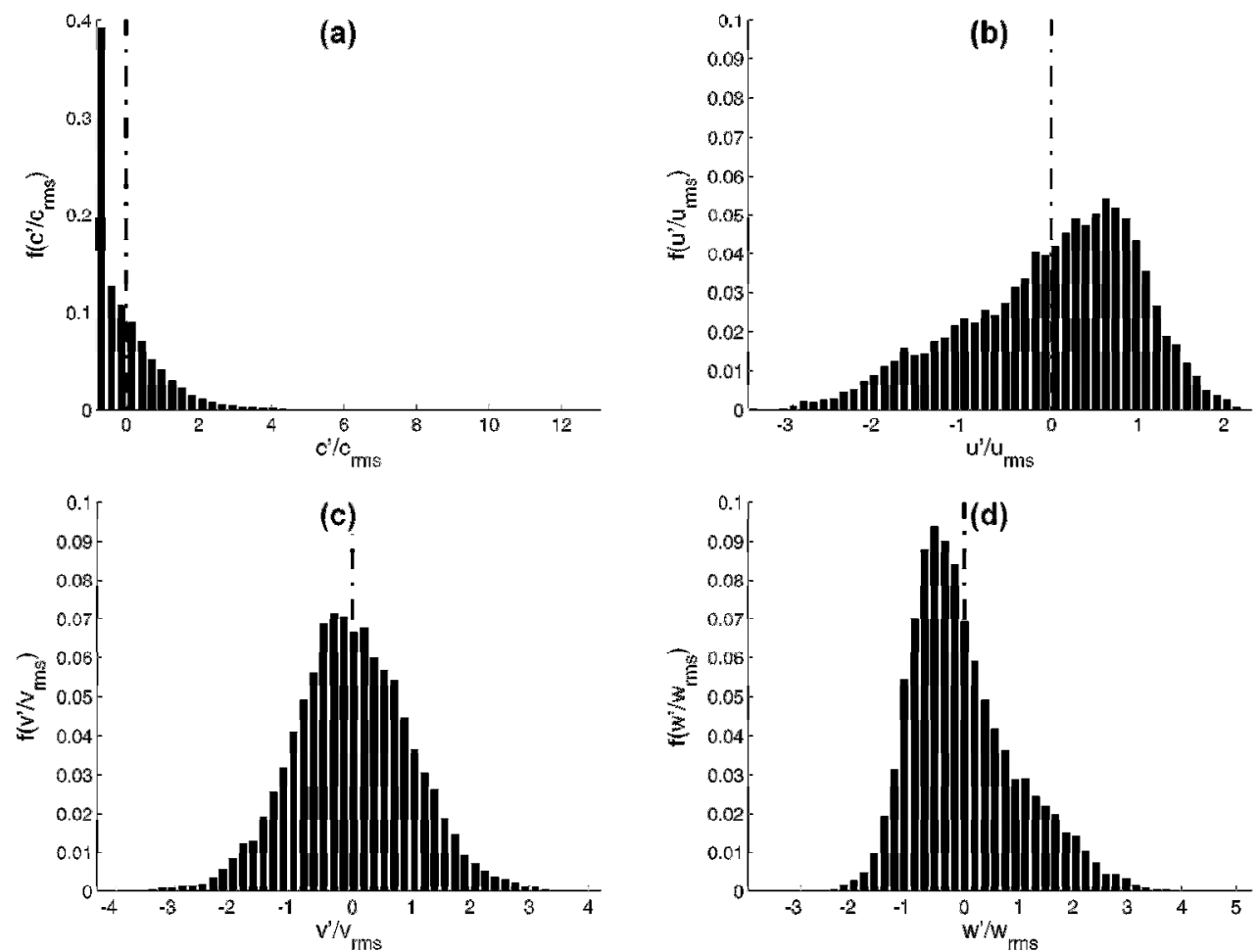

Figure 5. Point P1: frequency distribution histograms of (a) $c^{\prime} / c_{r m s}$, (b) $u^{\prime} / u_{r m s}$, (c) $v^{\prime} / v_{r m s}$, and (d) $w^{\prime} / w_{r m s}$. For each variable, the $\mathrm{x}$-axis limits correspond to the minimum and maximum sample values. The dashed line indicates the mean (zero) values of the fluctuations. Mean values: $K=3.00 ; U / U_{H}=0.84 ; V / U_{H}=0.01 ; W / U_{H}=-$ 0.11 .
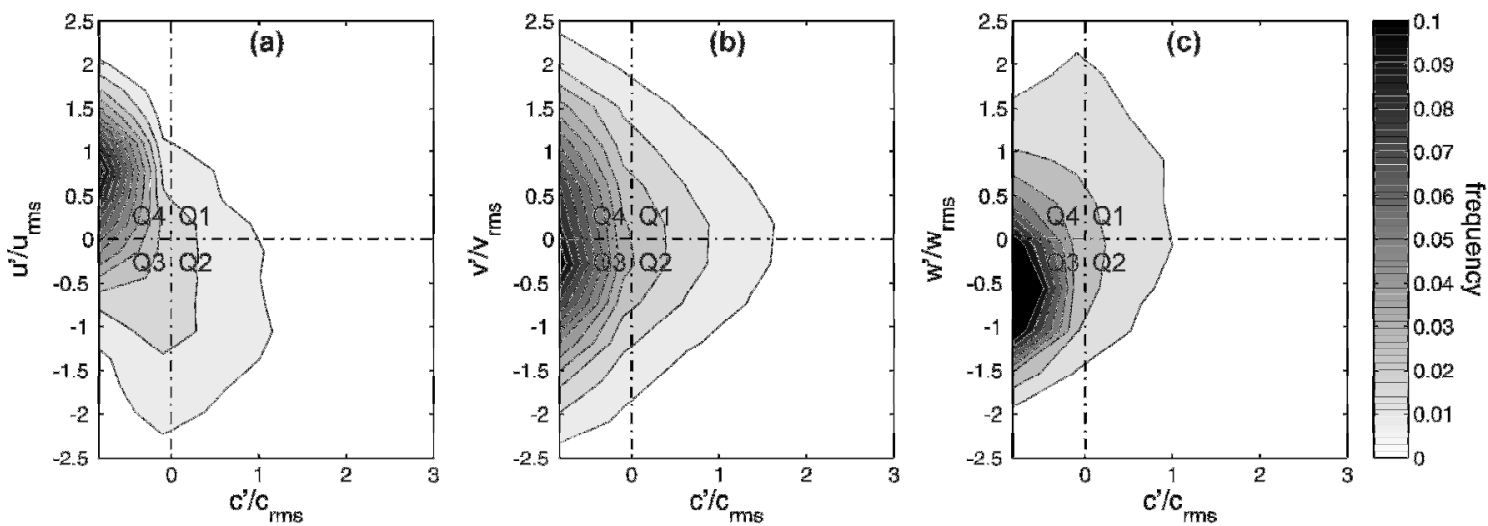

Figure 6. Point P1: bivariate histogram of frequency distribution for (a) $\left(c^{\prime} / c_{r m s} ; u^{\prime} / u_{r m s}\right)$, (b) $\left(c^{\prime} / c_{r m s} ; v^{\prime} / v_{r m s}\right)$, and (c) $\left(c^{\prime} / c_{r m s} ; w^{\prime} / w_{r m s}\right)$. 

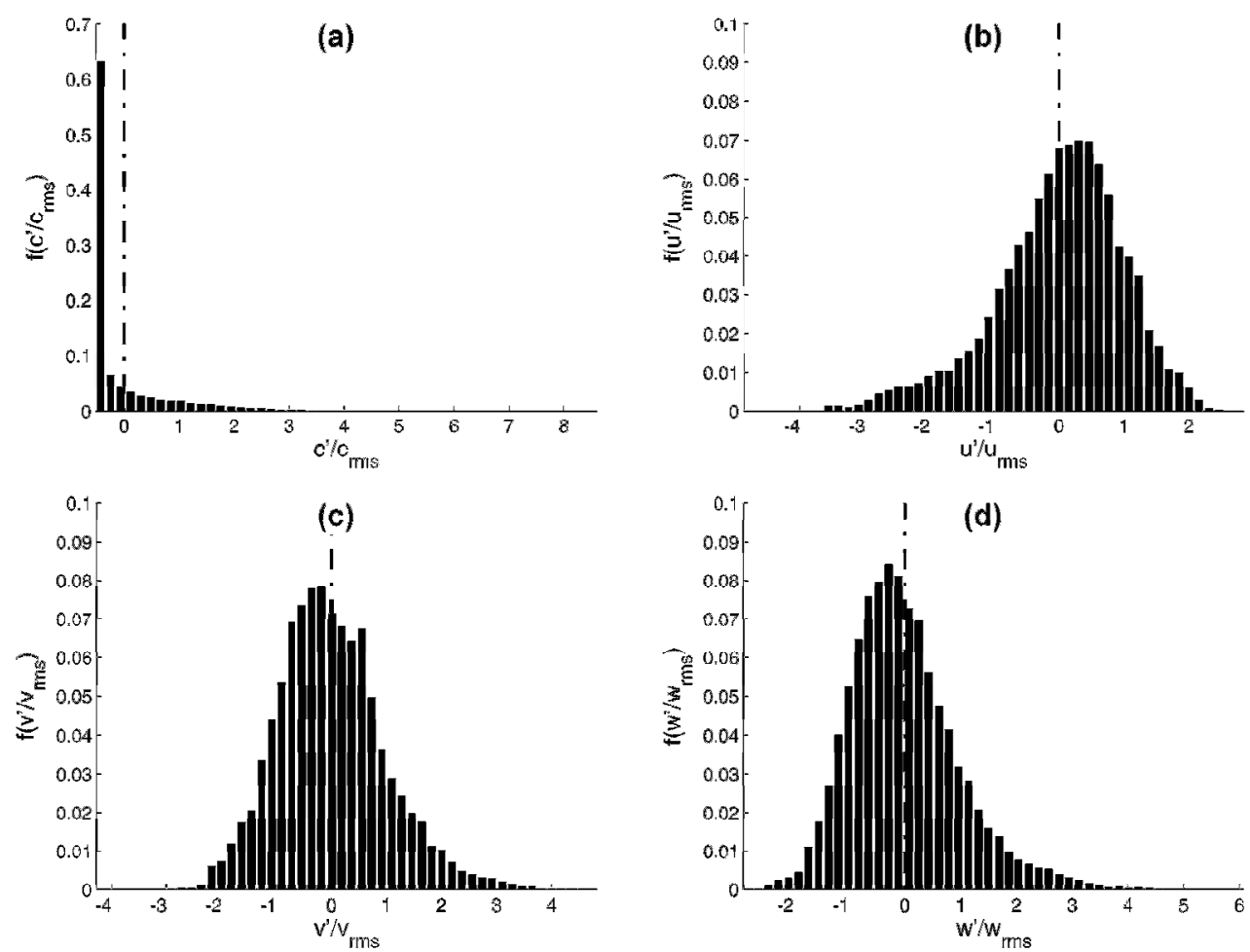

Figure 7. Point P2: frequency distribution histograms of (a) $c^{\prime} / c_{r m s}$, (b) $u^{\prime} / u_{r m s}$, (c) $v^{\prime} / v_{r m s}$, and (d) $w^{\prime} / w_{r m s}$. For each variable, the $\mathrm{x}$-axis limits correspond to the minimum and maximum sample values. The dashed line indicates the mean (zero) values of the fluctuations. Mean values: $K=0.50 ; U / U_{H}=0.94 ; V / U_{H}=-0.04 ; W / U_{H}=-$ 0.08 .
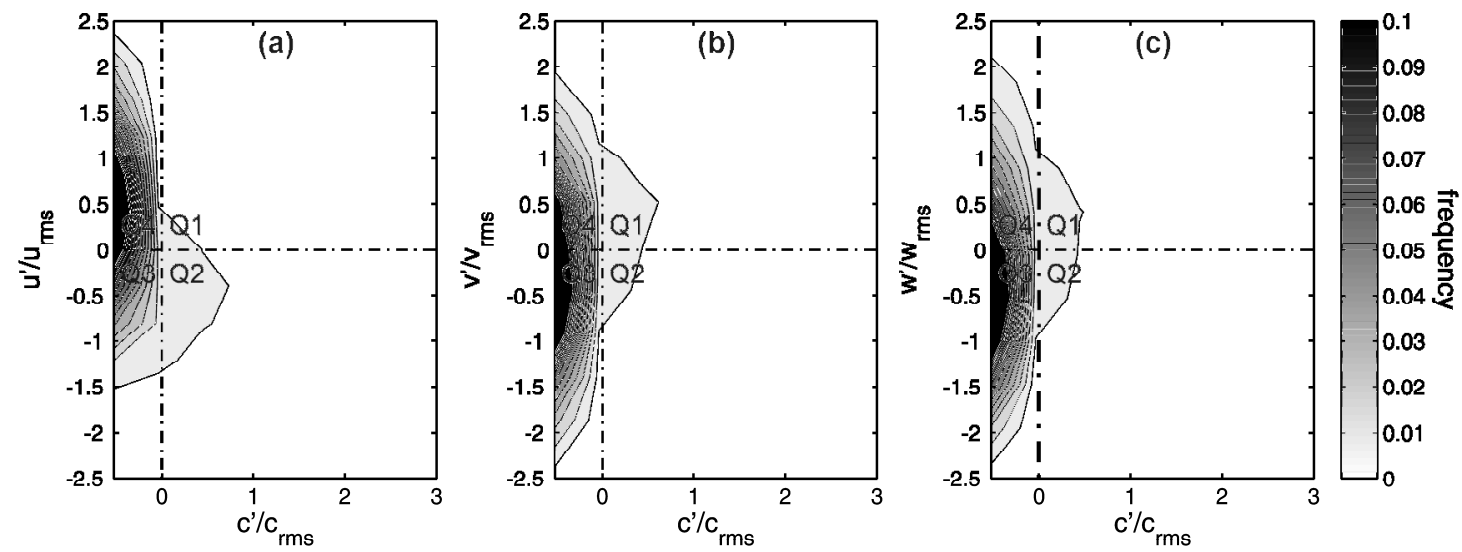

Figure 8. Point P2: bivariate histogram of frequency distribution for (a) $\left(c^{\prime} / c_{r m s} ; u^{\prime} / u_{r m s}\right)$, (b) $\left(c^{\prime} / c_{r m s} ; v^{\prime} / v_{r m s}\right)$, and (c) $\left(c^{\prime} / c_{r m s} ; w^{\prime} / w_{r m s}\right)$. 

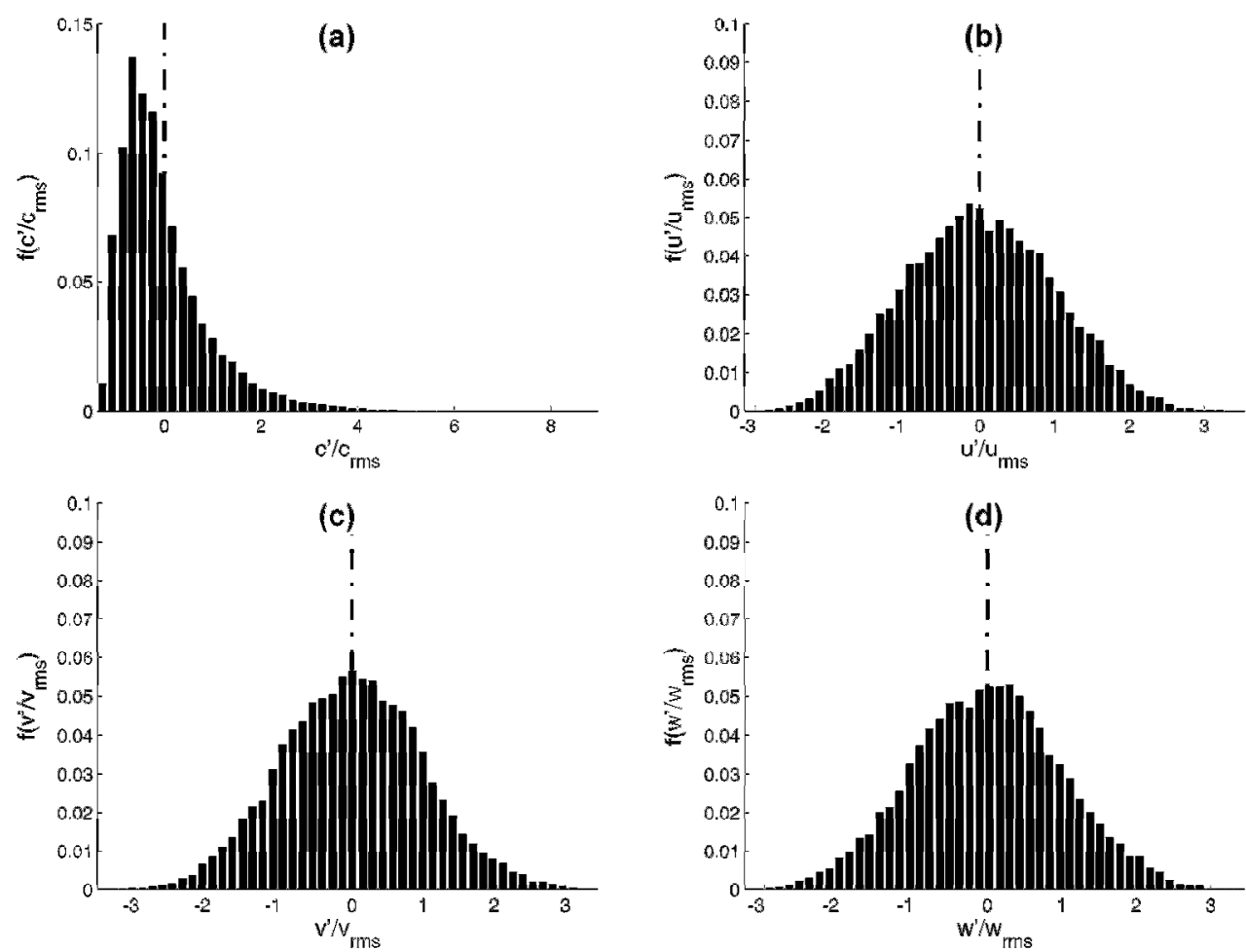

Figure 9. Point P3: frequency distribution histograms of (a) $c^{\prime} / c_{r m s}$, (b) $u^{\prime} / u_{r m s}$, (c) $v^{\prime} / v_{r m s}$, and (d) $w^{\prime} / w_{r m s}$. For each variable, the $\mathrm{x}$-axis limits correspond to the minimum and maximum sample values. The dashed line indicates the mean (zero) values of the fluctuations. Mean values: $K=2.46 ; U / U_{H}=0.15 ; V / U_{H}=0 ; W / U_{H}=-0.08$.
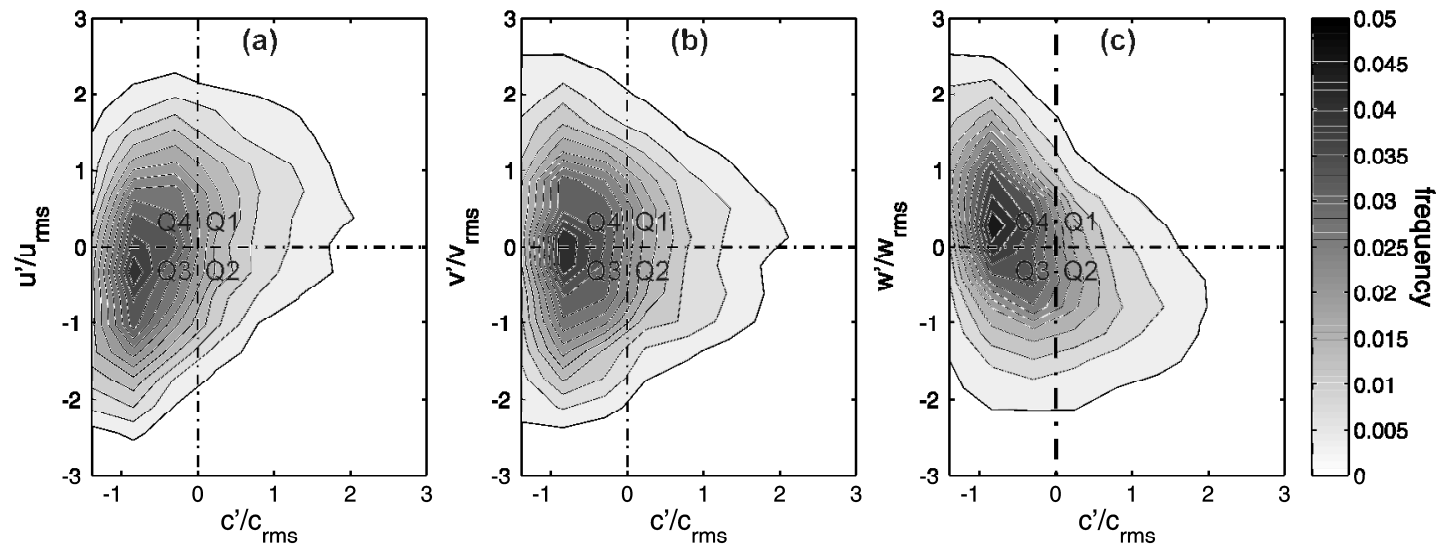

Figure 10. Point P3: bivariate histogram of frequency distribution for (a) $\left(c^{\prime} / c_{r m s} ; u^{\prime} / u_{r m s}\right)$, (b) $\left(c^{\prime} / c_{r m s} ; v^{\prime} / v_{r m s}\right)$, and (c) $\left(c^{\prime} / c_{r m s} ; w^{\prime} / w_{r m s}\right)$. 

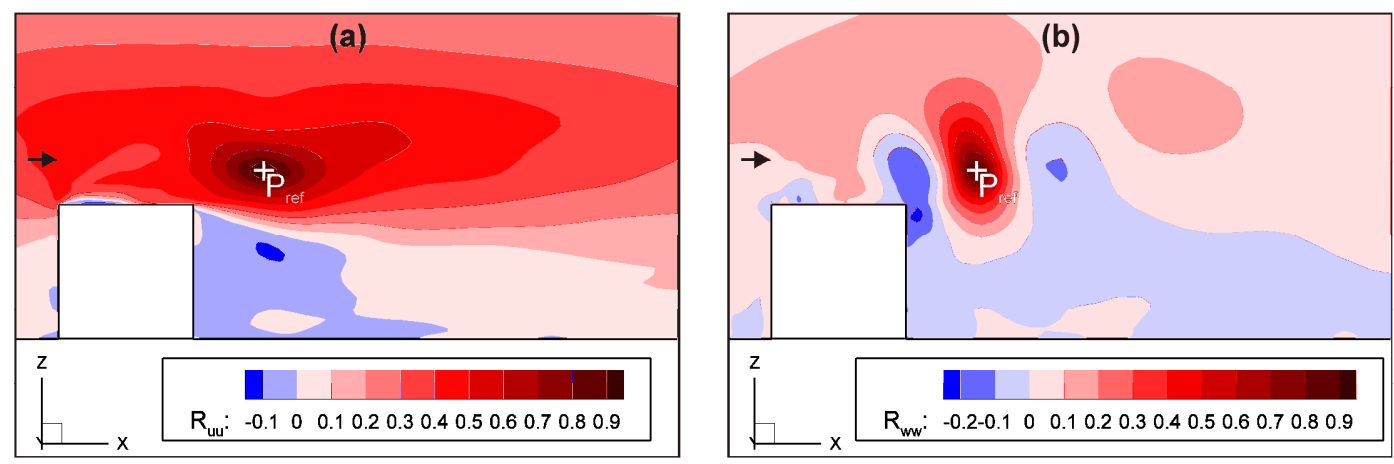

Figure 11. Contours of two-point velocity correlation coefficient in the vertical mid-plane $y / H=0$. (a) $R_{u u}\left(x, y, z, x_{r e f}, y_{r e f}, z_{r e f}\right)$ and (b) $R_{w w}\left(x, y, z, x_{r e f}, y_{r e f}, z_{r e f}\right)$, with $x_{r e f} / H=1.020, y_{r e f} / H=0$ and $z_{\text {ref }} / H=1.245$.
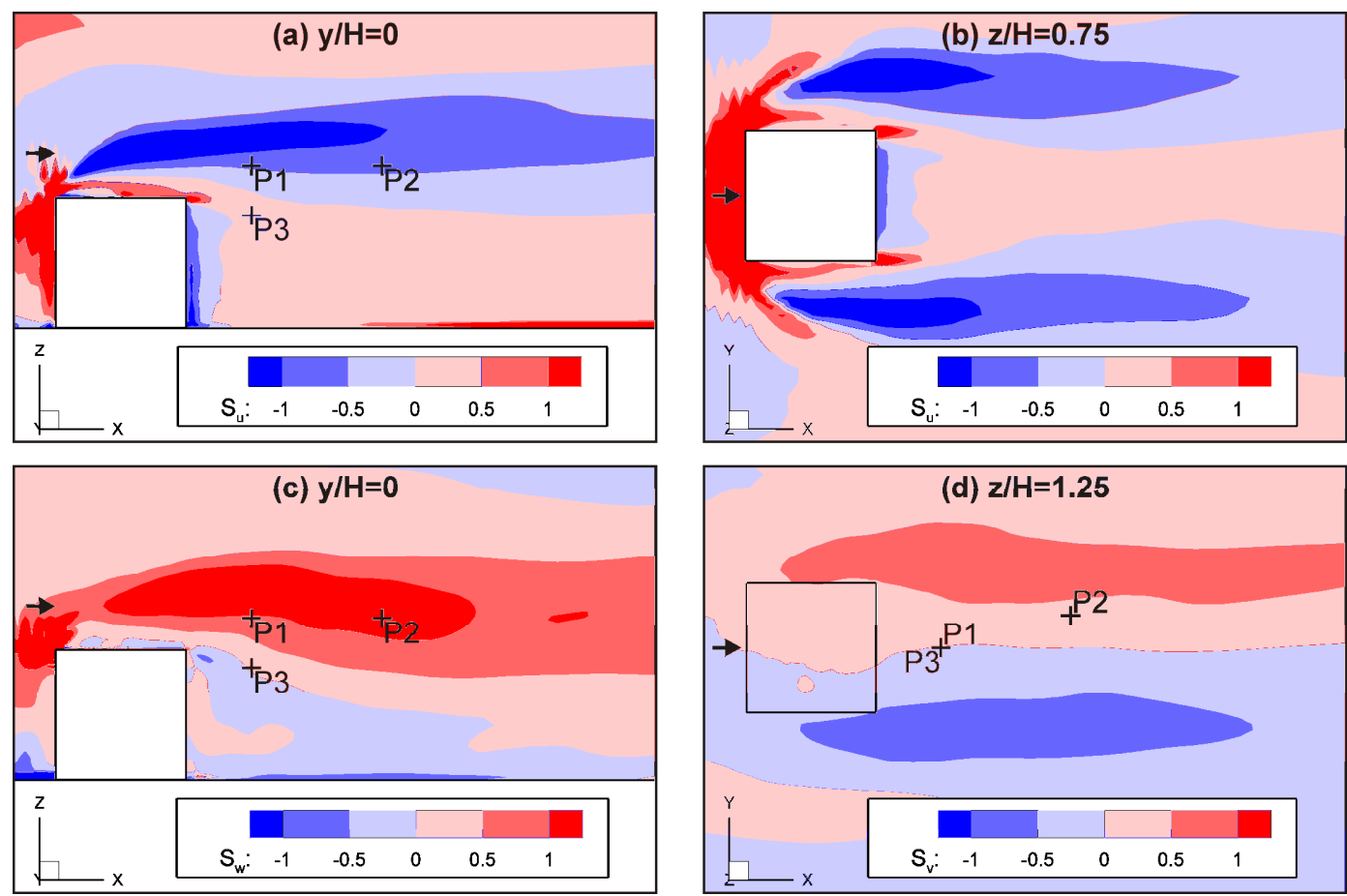

Figure 12. Contours of the skewness of the (a,b) streamwise, (c) vertical, and (d) lateral velocity in $(a, c)$ the vertical mid-plane, (b) the horizontal plane $z / H=0.75$ and (d) the horizontal plane $z / H=1.25$. 


\section{Tables}

Table 1. Non-dimensional coordinates of the monitoring points used in the present study.

\begin{tabular}{|l|l|l|l|}
\hline Point & $\mathrm{x} / \mathrm{H}$ & $\mathrm{y} / \mathrm{H}$ & $\mathrm{z} / \mathrm{H}$ \\
\hline P1 & 1 & 0 & 1.24 \\
\hline P2 & 2 & 0.25 & 1.24 \\
\hline P3 & 1 & 0 & 0.86 \\
\hline
\end{tabular}

Table 2. Non-dimensional statistics of concentration at the three monitoring points. The signs of the local spatial derivative of mean concentration are also given.

\begin{tabular}{|l|r|r|r|l|r|r|r|r|r|r|}
\hline & $\mathrm{K}=\mathrm{C} / \mathrm{C}_{0}$ & $\mathrm{c}_{\mathrm{rms}} / \mathrm{C}_{0}$ & $\mathrm{c}_{\mathrm{rms}} / \mathrm{C}$ & $\mathrm{S}_{\mathrm{c}}$ & $\mathrm{K}_{\mathrm{c}}$ & $\mathrm{c}^{\prime}{ }_{\min } / \mathrm{c}_{\mathrm{rms}}$ & $\mathrm{c}^{\prime}{ }_{\max } / \mathrm{c}_{\mathrm{rms}}$ & $\partial \mathrm{C} / \partial \mathrm{x}$ & $\partial \mathrm{C} / \partial \mathrm{y}$ & $\partial \mathrm{C} / \partial \mathrm{z}$ \\
\hline P1 & 3.00 & 3.62 & 1.21 & 2.39 & 11.10 & -0.83 & 13.08 & $<0$ & $\approx 0$ & $<0$ \\
\hline P2 & 0.50 & 0.97 & 1.94 & 2.98 & 11.42 & -0.52 & 8.60 & $<0$ & $<0$ & $<0$ \\
\hline P3 & 2.46 & 1.74 & 0.71 & 2.20 & 8.38 & -1.39 & 8.97 & $>0$ & $\approx 0$ & $>0$ \\
\hline
\end{tabular}

Table 3. Non-dimensional statistics of streamwise velocity at the three monitoring points.

\begin{tabular}{|l|r|r|r|r|r|r|r|r|}
\hline & $\mathrm{U}^{\prime} \mathrm{U}_{\mathrm{H}}$ & $\mathrm{u}_{\mathrm{rms}} / \mathrm{U}_{\mathrm{H}}$ & $\mathrm{lu}_{\mathrm{rms}} / \mathrm{Ul}^{\prime}$ & $\mathrm{S}_{\mathrm{u}}$ & \multicolumn{1}{c}{$\mathrm{K}_{\mathrm{u}}$} & $\mathrm{u}_{\min }^{\prime} / \mathrm{u}_{\mathrm{rms}}$ & $\mathrm{u}^{\prime}{ }_{\max } / \mathrm{u}_{\mathrm{rms}}$ & $\left\langle\mathrm{u}^{\prime} \mathrm{c}^{\prime}\right\rangle / \mathrm{Q}_{0}$ \\
\hline P1 & 0.84 & 0.26 & 0.31 & -0.57 & -0.20 & -3.51 & 2.33 & -0.403 \\
\hline P2 & 0.94 & 0.18 & 0.19 & -0.67 & 0.71 & -4.87 & 2.85 & -0.094 \\
\hline P3 & 0.15 & 0.20 & 1.33 & 0.06 & -0.30 & -3.15 & 3.54 & 0.089 \\
\hline
\end{tabular}

Table 4. Non-dimensional statistics of lateral velocity at the three monitoring points.

\begin{tabular}{|l|r|r|r|l|r|r|r|r|}
\hline & $\mathrm{V} / \mathrm{U}_{\mathrm{H}}$ & $\mathrm{v}_{\mathrm{rms}} / \mathrm{U}_{\mathrm{H}}$ & $\mathrm{I}_{\mathrm{rms}} / \mathrm{VI}$ & $\mathrm{S}_{\mathrm{v}}$ & \multicolumn{1}{c}{$\mathrm{K}_{\mathrm{v}}$} & $\mathrm{v}^{\prime}{ }_{\text {min }} / \mathrm{v}_{\mathrm{rms}}$ & $\mathrm{v}^{\prime}{ }_{\text {max }} / \mathrm{v}_{\mathrm{rms}}$ & $\left\langle\mathrm{v}^{\prime} \mathrm{c}^{\prime}\right\rangle / \mathrm{Q}_{0}$ \\
\hline P1 & 0.01 & 0.17 & 17 & 0.02 & 0.34 & -4.33 & 4.21 & -0.008 \\
\hline P2 & -0.04 & 0.11 & 2.75 & 0.52 & 0.87 & -4.27 & 4.83 & 0.040 \\
\hline P3 & 0.00 & 0.20 & - & 0.04 & -0.06 & -3.58 & 3.46 & -0.006 \\
\hline
\end{tabular}

Table 5. Non-dimensional statistics of vertical velocity at the three monitoring points.

\begin{tabular}{|l|r|r|r|l|r|r|r|r|}
\hline & $\mathrm{W} / \mathrm{U}_{\mathrm{H}}$ & $\mathrm{W}_{\mathrm{rms}} / \mathrm{U}_{\mathrm{H}}$ & $\mathrm{I}_{\mathrm{rms}} / \mathrm{Wl}$ & $\mathrm{S}_{\mathrm{w}}$ & \multicolumn{1}{l}{$\mathrm{K}_{\mathrm{w}}$} & $\mathrm{W}^{\prime}{ }_{\text {min }} / \mathrm{w}_{\mathrm{rms}}$ & $\mathrm{W}^{\prime}{ }_{\max } / \mathrm{w}_{\mathrm{rms}}$ & $\left\langle\mathrm{W}^{\prime} \mathrm{c}^{\prime}\right\rangle / \mathrm{Q}_{0}$ \\
\hline P1 & -0.11 & 0.15 & 1.36 & 0.80 & 0.63 & -3.97 & 5.29 & 0.160 \\
\hline P2 & -0.08 & 0.11 & 1.37 & 0.88 & 1.61 & -2.89 & 6.08 & 0.023 \\
\hline P3 & -0.08 & 0.21 & 2.62 & 0.04 & -0.16 & -3.26 & 3.46 & -0.127 \\
\hline
\end{tabular}

Table 6. Numbering and definitions of the quadrants. The names of the corresponding events hold for the vertical direction, following (Chen, 1990).

\begin{tabular}{|l|c|l|l|}
\hline Quadrant & $\mathrm{u}_{\mathrm{i}}{ }^{\prime}$ & $\mathrm{c}^{\prime}$ & Name (z-direction) \\
\hline Q1 & $>0$ & $>0$ & Ejection \\
\hline Q2 & $<0$ & $>0$ & Inward interaction \\
\hline Q3 & $<0$ & $<0$ & Sweep \\
\hline Q4 & $>0$ & $<0$ & Outward interaction \\
\hline
\end{tabular}

